\title{
Trajectory Calculation as Forecasting Support Tool for Dust Storms
}

\author{
Sultan Al-Yahyai ${ }^{1}$ and Yassine Charabi ${ }^{2}$ \\ ${ }^{1}$ Oman National Meteorological Service, Public Authority for Civil Aviation, Muscat International Airport, P.O. Box 1, \\ Muscat 111, Oman \\ ${ }^{2}$ Department of Geography, College of Arts \& Social Sciences, Sultan Qaboos University, P.O. Box 42, Al-Khoud, Muscat, Oman
}

Correspondence should be addressed to Sultan Al-Yahyai; s.alyahyai@gmail.com

Received 25 December 2013; Revised 24 March 2014; Accepted 4 April 2014; Published 24 April 2014

Academic Editor: Umesh Kulshrestha

Copyright (C) 2014 S. Al-Yahyai and Y. Charabi. This is an open access article distributed under the Creative Commons Attribution License, which permits unrestricted use, distribution, and reproduction in any medium, provided the original work is properly cited.

In arid and semiarid regions, dust storms are common during windy seasons. Strong wind can blow loose sand from the dry surface. The rising sand and dust is then transported to other places depending on the wind conditions (speed and direction) at different levels of the atmosphere. Considering dust as a moving object in space and time, trajectory calculation then can be used to determine the path it will follow. Trajectory calculation is used as a forecast supporting tool for both operational and research activities. Predefined dust sources can be identified and the trajectories can be precalculated from the Numerical Weather Prediction (NWP) forecast. In case of long distance transported dust, the tool should allow the operational forecaster to perform online trajectory calculation. This paper presents a case study for using trajectory calculation based on NWP models as a forecast supporting tool in Oman Meteorological Service during some dust storm events. Case study validation results showed a good agreement between the calculated trajectories and the real transport path of the dust storms and hence trajectory calculation can be used at operational centers for warning purposes.

\section{Introduction}

Dust storms, a type of dust events, are in most cases the result of turbulent winds, including convective haboobs, which raise large quantities of dust from desert surfaces and reduce visibility to less than $1 \mathrm{~km}$ [1]. Dust storms directly affect visibility and impact daily commercial, transport, and military operations near desert regions [2]. Due to their effects on human health and activities, several aspects of dust storms have been recently investigated. These include dust characteristic, dust sources, transport process, and dust forecast. In addition, some studies tried to link the increase of the dust storm frequency with the climate change. Dust sampled over the north of the Arabian Peninsula for 2009 and pre-2009 was compared in [3]. It was concluded that there was a major change in the characteristic of the transformed dust which indicates a possible role for climate change.

Wind condition plays a major role in the generation and transport of dust storm. In [4], dust storm data was correlated with the monthly extreme wind velocity. The results demonstrate that the wind regime (strength and variability) is a key control on the sand and dust deposition during dust storm. Therefore, the better the forecast of the wind condition, the better the forecast of the dust storm generation and transport. Several dust forecasting models were developed for operational and research use at server institutes. Examples of such models are presented in [57]. An evaluation of the Community Aerosol and Radiation Model for Atmospheres (CARMA) [8] developed by the United States Air Force Weather Agency was presented in [2] over Sahara region. CARMA is initialized by assimilating the meteorological forecast data from the MM5 numerical weather prediction model [2]. The model also incorporates the global dust source database developed by Ginoux in [9]. The model uses 10 particle size bins which cover dust particles with radii from $0.5 \mu \mathrm{m}$ to $10.0 \mu \mathrm{m}$. In CARMA, dust aerosols are lofted by vertical advection and diffusion. The vertical diffusion is calculated using the MM5 input meteorology. The 


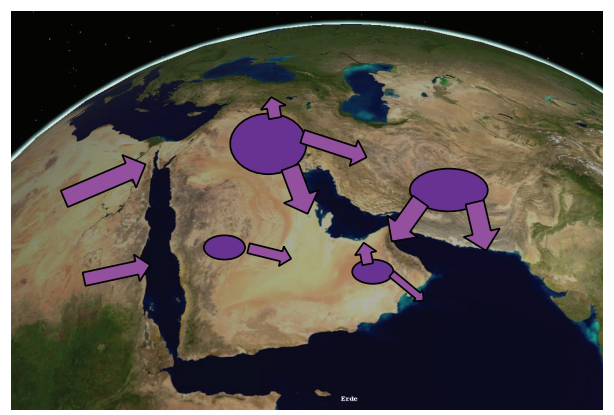

Figure 1: Dust sources surrounding the Arabian Peninsula.

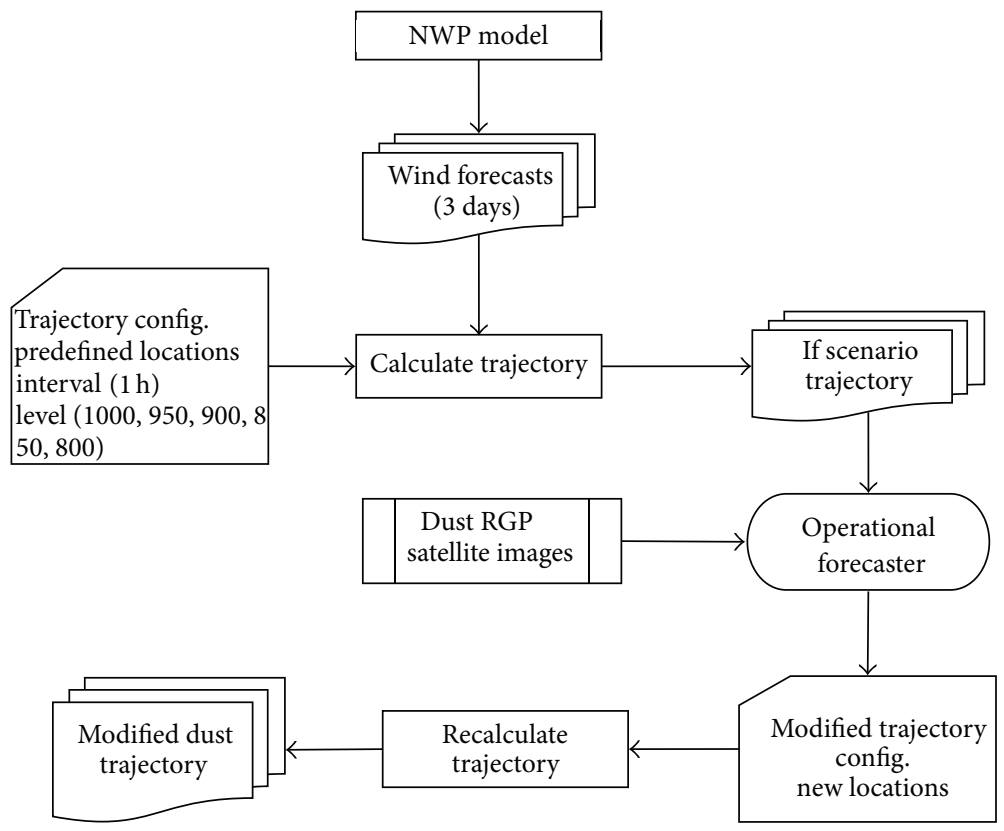

Figure 2: Data flow diagram of the system.

model calculates the vertical potential temperature, sensible heat flux, Monin-Obukhov length, and friction velocity using the MM5 meteorological profile at each grid point. The model then calculates the vertical diffusion for each vertical level following the method developed by Zhang and Anthes in [10].

In this paper, a dust storm forecast supporting tool is proposed using forward trajectory calculation. Considering dust as a moving object in space and time, forward trajectory calculation then can be used to determine the path it will follow. The position of each trajectory is given by [11]

$$
\begin{aligned}
x_{i}(t+\Delta t) & =x_{i}(t)+v_{i}(t) \Delta t, \\
v_{i} & =v_{i}^{-}+v_{i}^{\prime} .
\end{aligned}
$$

The velocity $v_{i}$ is composed of the grid scale velocity $v_{i}^{-}$ and the turbulent fluctuation $v_{i}^{\prime}$, which is computed by solving the Langevin diffusion equation using a Markov chain formulation [12]. The trajectories are calculated from 3D wind fields and surface pressure of the numerical weather perdition (NWP) model. The trajectory equations are solved numerically at high numerical accuracy of the second order.
The interpolation of the NWP fields to the trajectory location is linear in time, but cubic in $3 \mathrm{D}$ space (different constant pressure levels). In this paper, a forecast supporting tool was developed at Oman National Meteorological Service using trajectory calculation. Predefined dust sources were identified and the trajectories were calculated after each run of the NWP model over those sources. On the other hand, operational forecaster can adjust the start location of the trajectories to match the exact location of the dust storm. Finally, this paper presents a case study for using trajectory calculation. The system utilized NWP data from the high resolution $(7 \mathrm{~km})$ Oman regional model. Two dust storm events during March 2012 are presented. The rest of the paper is organized as follow. Section 2 presents the applied methodology. Case study results are presented on Section 3. Finally, Section 4 concludes the paper.

\section{Methodology}

According to [13], four main dust sources were identified in the area, namely, Tigris and Euphrates rivers basin, Sistan 
TABLE 1: COSMO model configuration.

\begin{tabular}{ll}
\hline Details & Configuration \\
\hline Model domain & $35.0 \mathrm{E}-78 \mathrm{E}(\mathrm{ie}=769), 7.0 \mathrm{~N}-35.25 \mathrm{~N}(\mathrm{je}=453), 40$ vertical layers \\
\hline Model equations & $\begin{array}{l}\text { Nonhydrostatic, full compressible hydrothermodynamical equations in advection form. Subtraction } \\
\text { of a hydrostatic base state at rest }\end{array}$ \\
\hline Prognostic variables & $\begin{array}{l}\text { Horizontal and vertical Cartesian wind components, pressure perturbation, temperature, specific } \\
\text { humidity, and cloud water content. Optionally: cloud ice content, turbulent kinetic energy, specific } \\
\text { water content of rain, snow, and graupel }\end{array}$ \\
\hline Coordinate system & $\begin{array}{l}\text { Generalized terrain-following height coordinate with rotated geographical coordinates and user } \\
\text { defined grid stretching in the vertical }\end{array}$ \\
\hline Initial conditions & Global German model analysis at 00, 12 UTC \\
\hline Boundary conditions & Global German model (20 km); 60 vertical layers \\
\hline Surface layer parameterization & Turbulent kinetic energy \\
\hline Convection parameterization & Tiedtke mass-flux convection \\
\hline
\end{tabular}

and Baloushistan basin, East of Alhejaz Mountains basin, and Southwest Alhajar Mountains basin. The sources are marked in Figure 1. The proposed trajectory dust forecast supporting system is implemented to work in two different modes. The first mode is called "if scenario" mode. The second mode is called "real time" mode. In the "if scenario" mode, the dust trajectory is calculated for each dust source after each NWP model run and for different time horizons. This mode is used to answer the question "what are the possible paths if a dust storm is generated from one of the sources?" This mode provides the operational forecaster with a set of possible scenarios for different altitudes of the atmosphere. The "real time" mode is used by the operational forecaster once the dust storm is detected using satellite RBG composite. Operational forecaster can modify the location of the dust storm according to the latest observations and then the trajectory paths will be recalculated accordingly. This mode is used to adjust the first guess of the "if scenario" mode.

Figure 2 shows the data flow diagram of the system. The proposed system is loosely coupled with the operational NWP model. Therefore, the output (hourly wind forecast) of any NWP model is used as input to the trajectory calculation system. The system requires some basic configuration including the predefined starting locations, output interval, and the required levels. At this stage, the system will provide trajectory calculation forecast of the "what if" scenario. The operational forecaster who is monitoring the dust raising using the dust satellite RGB can modify the starting location of the trajectory based on his observations from the satellite images. Then the trajectory calculation system will rerun the trajectory based on the updated real time information.

Figure 3 shows an example of the "if scenario" output of the system at March, 17, 2012. It can be seen from the RBG composite satellite image that there was no dust storm detected at this time. For each dust source, two sets of trajectories are calculated to capture the spatial structure of the expected dust storm. Trajectories for different altitude, namely, $1000 \mathrm{hPa}, 950 \mathrm{hPa}, 900 \mathrm{hPa}, 850 \mathrm{hPa}$, and $800 \mathrm{hPa}$, are calculated for each source. From this "if scenario" output of the system, operational forecasters need to keep an eye on any dust storm development over Tigris and Euphrates

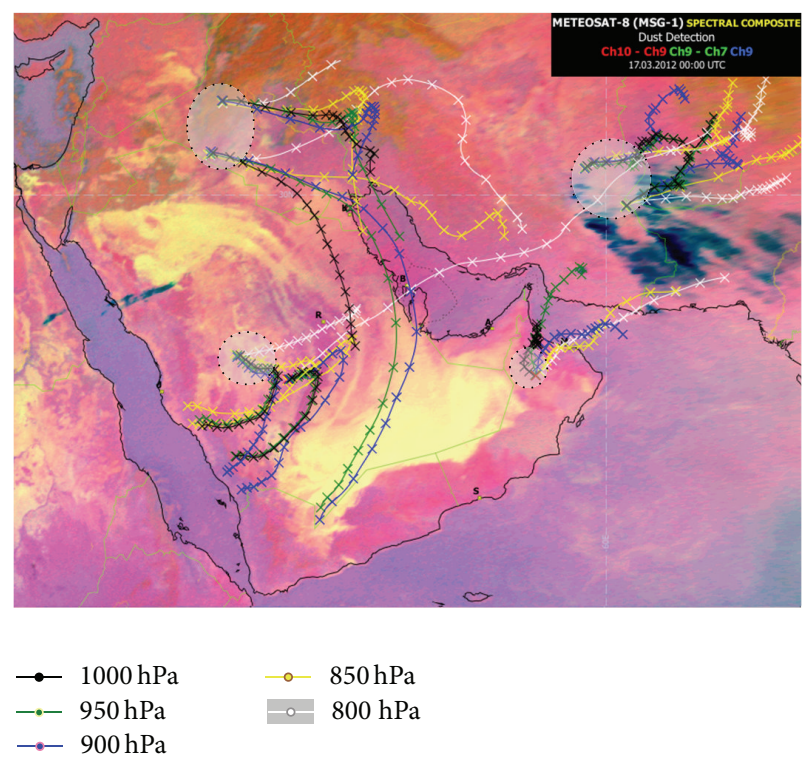

FIGURE 3: "If scenario" output of the system based on the NWP model run at 17/3/2012 00 UTC.

rivers basin because it may be transported to the area. The "if scenario" of this case predicts that any dust storm development over Sistan Basin and Baloushistan or East of Alhejaz Mountains will not be transported to Oman.

For the trajectory calculation, Oman regional model is used to generate the required wind field data. Oman weather service is running Consortium for small-scale modeling (COSMO) mode [14]. Oman weather service runs COSMO at $7 \mathrm{~km}$ resolution. Table 1 summarizes the main configurations used in COSMO model.

\section{Case Study Results}

Synoptically, on March 17, 2012, at 08UTC, a dust storm was developed as a result of winter Shamal wind crossing Iraq towards Arabian Gulf. The dust storm affected all Arabian Gulf countries and the visibility was reduced to less than 


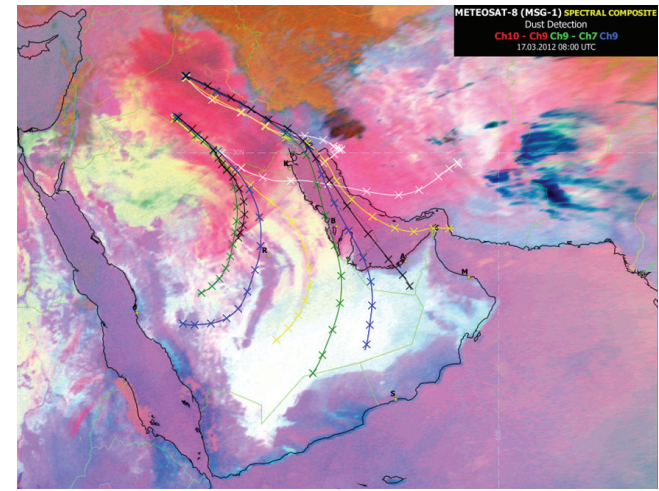

(a)
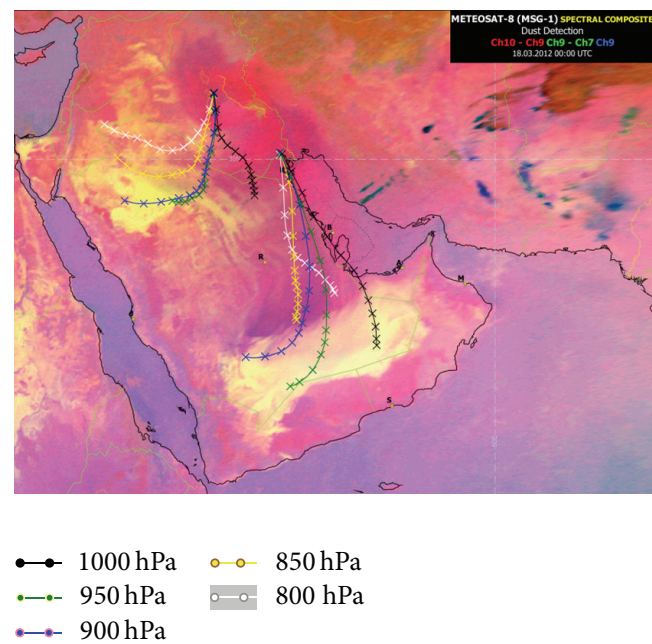

(c)

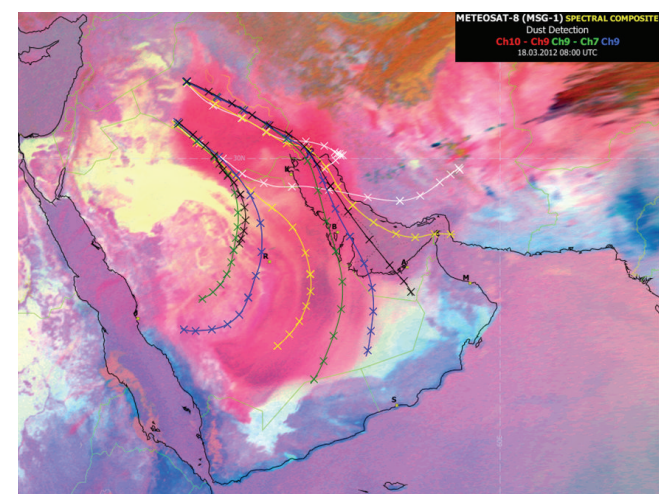

(b)
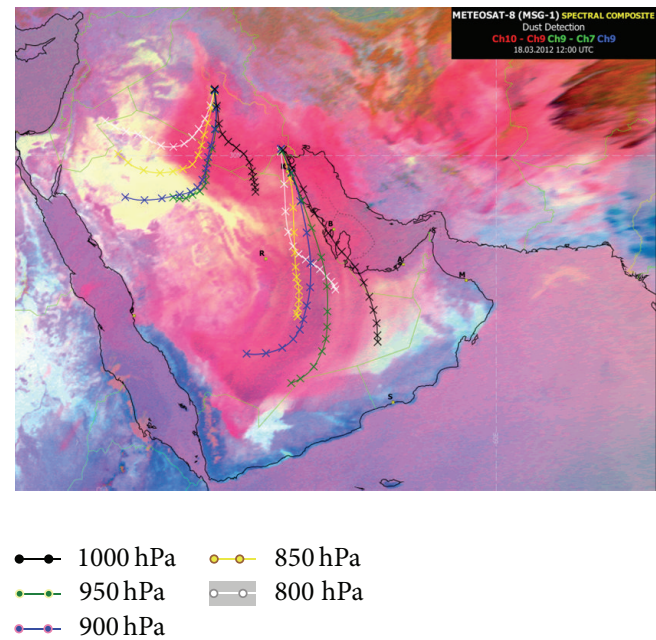

(d)

FIgURE 4: System out for the dust storm event over Tigris and Euphrates rivers basin starting from March 17, 2012.

$800 \mathrm{~m}$. The upper air profile of Iraq desert (taken from NWP models) showed that the northwesterly wind was extended up to $700 \mathrm{hPa}$ level due to high pressure system over Arabian Peninsula that extended from Siberian high. After a trough of low pressure system at $500 \mathrm{hPa}$ level passed over Iraq desert, the northwesterly wind at surface was intensified. The intensified northwesterly wind causes dust to rise from Iraq desert area and move in a southeasterly direction affecting Iraq, Kuwait, Bahrain, Qatar, KSA, UAE, and reached Oman and Yemen. Normally, the northwesterly wind persists for more than one day.

On March 18, 2012, 1200UTC another dust storm formed over Iran desert and moved southerly towards Sultanate of Oman and reduced the visibility to less than $500 \mathrm{~m}$ with maximum wind speed of 25 knots sometimes gusting to 35 Knots. The system of high pressure located over Iran desert as extension of Siberian high reached up to $700 \mathrm{hPa}$ resulting in an increase in the wind speed aloft. A $500 \mathrm{hPa}$ trough (which crossed Iraq before) passed Iran desert, the high pressure intensified, and the surface northerly wind strengthened and blew the dust towards the south to Oman sea coasts.
3.1. System Validation. When the dust storm was detected over the Tigris and Euphrates rivers basin at March 17, 2012, 08UTC, the trajectories were calculated based on the NWP model run at March 17, 2012, 00UTC. Results showed that the storm will move southeasterly across the Arabian Gulf and then will make a turn to the west as shown in Figure 4(a). Figure 4(b) shows the storm $24 \mathrm{~h}$ later (March $18,2013,08 \mathrm{UTC})$. It can be seen that the trajectories which were generated in the previous day were able to predict the movement of the storm.

On March 18, 2012, 00UTC, the center of the dust storm moved southeasterly over Kuwait. Therefore, trajectories were recalculated starting from the new location and using the latest NWP model data as shown in Figure 4(c). Figure 4(d) shows the storm $12 \mathrm{~h}$ later (March 19, 2012, 12UTC). It can be seen that the trajectories were able to simulate the movement of the storm.

While the dust storm was still crossing the Arabian Peninsula, a new dust storm was detected over Sistan and Baloushistan basin at March 18, 2012, 12UTC. Based on the model run of 00UTC of the same day, trajectories were calculated for this storm. It was forecasted that part of 


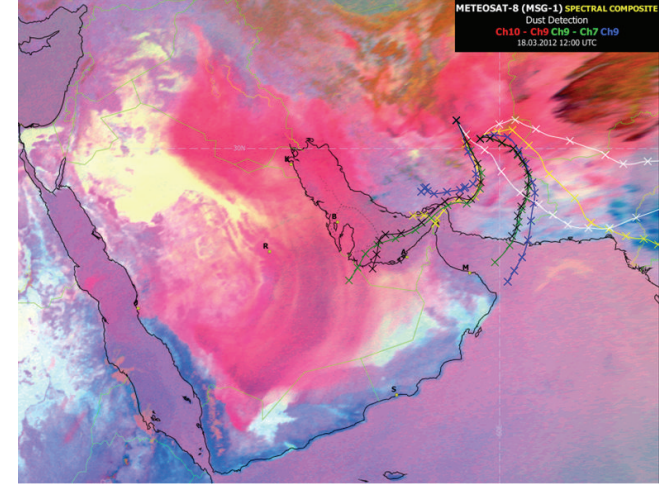

(a)
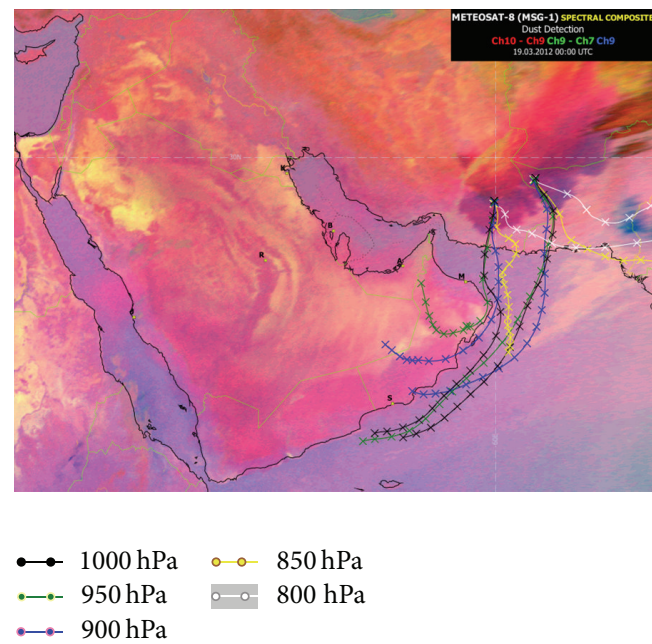

(c)

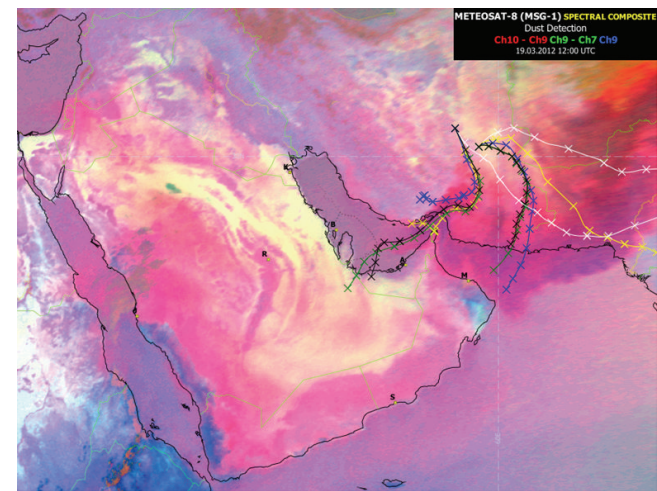

(b)
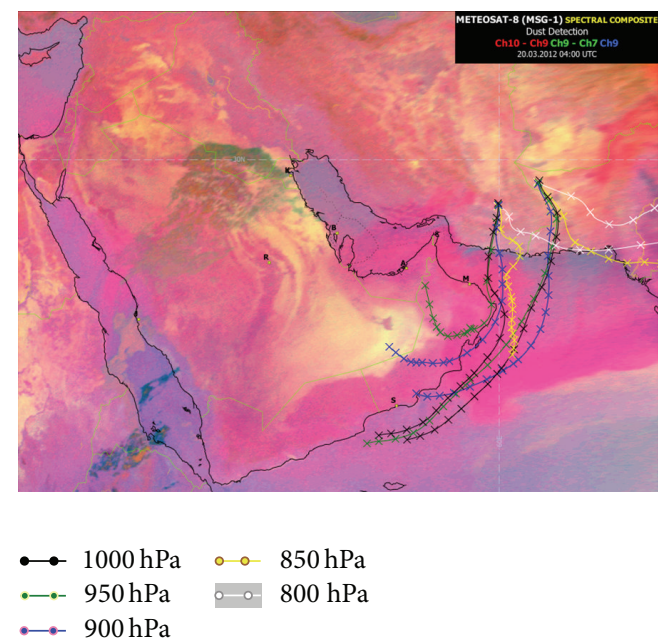

(d)

Figure 5: System out for the dust storm event over Sistan and Baloushistan basin starting from March 18, 2012.

the storm will cross the Strait of Hormuz to the Arabian Gulf and the other part will move to Oman Sea and then to Muscat as shown in Figure 5(a).

The top right part of Figure 5(b) shows the location of the dust storm at March 19, 2012, 12UTC (24 h later) with high agreement with the predicted trajectories. On March 19, 2012, 00 UTC, new trajectories were generated based on the latest model run and starting from the new location of the storm as shown in Figure 5(c). This model run was validated using the satellite pictures from March 30, 2012, 00UTC (24 h later). It can be seen, from Figure 5(d), that the trajectories were able to simulate the extent of the storm along the Omani coasts and over Masirah island.

\section{Conclusion}

This paper presented a dust storm forecast supporting system using trajectory calculation from numerical weather prediction models. The system was developed at Oman Meteorological Service and validated using the high resolution $(7 \mathrm{~km})$ Oman regional model. The system was implemented to run after each NWP model run and generate "if scenarios" for each time horizon forecast and over four surrounding dust sources. Users can correct the location of the dust storm based on the satellite observation and recalculate the trajectories accordingly. The paper also presented a system validation using two cases of dust storm during March 2012. The validation results showed a good agreement between the calculated trajectories and the real transport path of the dust storms emphasizing the usefulness of such trajectories for warning purposes. It is important to mention that the quality trajectory calculation is a function of the quality of the used NWP model forecast. The higher the quality of the NWP model wind forecast the higher the accuracy of the dust trajectory transport paths.

\section{Conflict of Interests}

The authors declare that there is no conflict of interests regarding the publication of this paper.

\section{Acknowledgment}

The authors would like to acknowledge The Research Council (Oman) for supporting this research article based on the project "Solar and wind prospects in Oman" 


\section{References}

[1] A. S. Goudie, "Dust storms: recent developments," Journal of Environmental Management, vol. 90, no. 1, pp. 89-94, 2009.

[2] B. H. Barnum, N. S. Winstead, J. Wesely et al., "Forecasting dust storms using the CARMA-dust model and MM5 weather data," Environmental Modelling and Software, vol. 19, no. 2, pp. 129140, 2004.

[3] W. Hamza, M. R. Enan, H. Al-Hassini, J.-B. Stuut, and D. DeBeer, "Dust storms over the Arabian Gulf: a possible indicator of climate changes consequences," Aquatic Ecosystem Health and Management, vol. 14, no. 3, pp. 260-268, 2011.

[4] M. Qiang, F. Chen, A. Zhou, S. Xiao, J. Zhang, and Z. Wang, "Impacts of wind velocity on sand and dust deposition during dust storm as inferred from a series of observations in the northeastern Qinghai-Tibetan Plateau, China," Powder Technology, vol. 175, no. 2, pp. 82-89, 2007.

[5] S. Ničković and S. Dobričić, "A model for long-range transport of desert dust," Monthly Weather Review, vol. 124, no. 11, pp. 2537-2544, 1996.

[6] T. F. Hogan and T. E. Rosmond, "The description of the Navy operational global atmospheri prediction system's spectral forecast model," Monthly Weather Review, vol. 119, no. 8, pp. 1786-1815, 1991.

[7] Y. Shao, "A model for mineral dust emission," Journal of Geophysical Research D: Atmospheres, vol. 106, no. 17, pp. 2023920254, 2001.

[8] O. B. Toon, R. P. Turco, D. Westphal, R. Malone, and M. S. Liu, "A multidimensional model for aerosols: description of computational analogs," Journal of the Atmospheric Sciences, vol. 45, no. 15, pp. 2123-2143, 1988.

[9] P. Ginoux, M. Chin, I. Tegen et al., "Sources and distributions of dust aerosols simulated with the GOCART model," Journal of Geophysical Research D: Atmospheres, vol. 106, no. 17, pp. 2025520273, 2001.

[10] D. Zhang and R. A. Anthes, "A high-resolution model of the planetary boundary layer - sensitivity tests and comparisons with SESAME-79 data," Journal of Applied Meteorology, vol. 21, no. 11, pp. 1594-1609, 1982.

[11] B. Fay, L. Neunhäuserer, and H. Glaab, "Results of first urbanisation steps in LM and application of very high-resolution LM simulations to air pollution models in selected air pollution episodes," in Proceedings of the 6th International SRNWPworkshop on non-hydrostatic modelling abstracts, J. Steppeler, Ed., DWD, Offenbach, November 2005.

[12] B. J. Legg and M. R. Raupach, "Markov-chain simulation of particle dispersion in inhomogeneous flows: the mean drift velocity induced by a gradient in Eulerian velocity variance," Boundary-Layer Meteorology, vol. 24, no. 1, pp. 3-13, 1982.

[13] H. Al-Badi, Remote sensing of dust clouds and determining their main sources that affect the Arabian peninsula [M.S. thesis], University of Dundee, 2006.

[14] G. Doms and U. Schattler, A Description of the Nonhydrostatic Regional Model LM. Part I: Dynamics and Numerics, Germany Weather Service, 2012, http://www.cosmo-model.org/. 

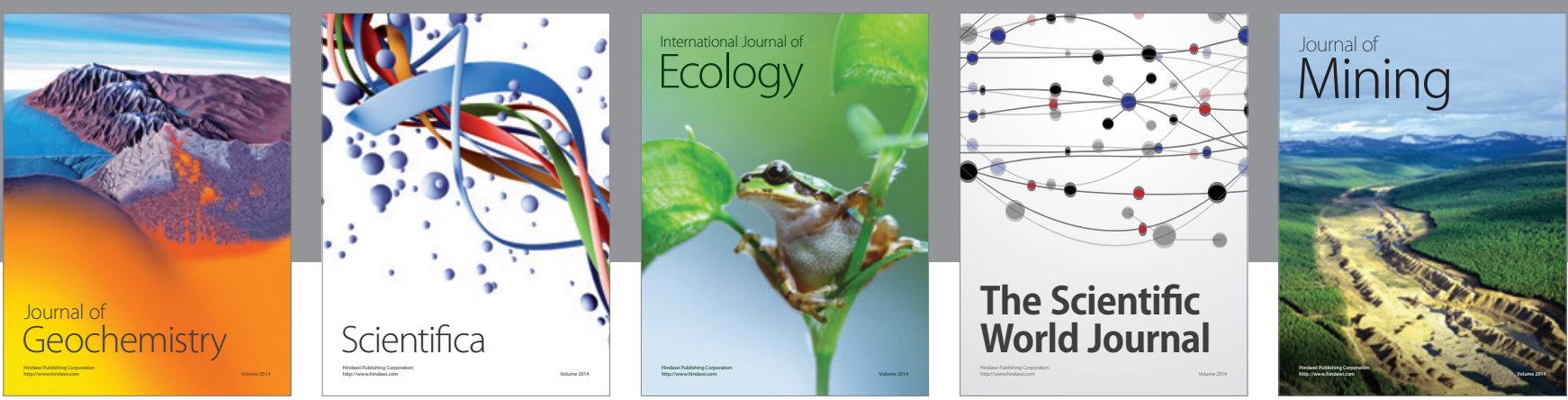

The Scientific World Journal
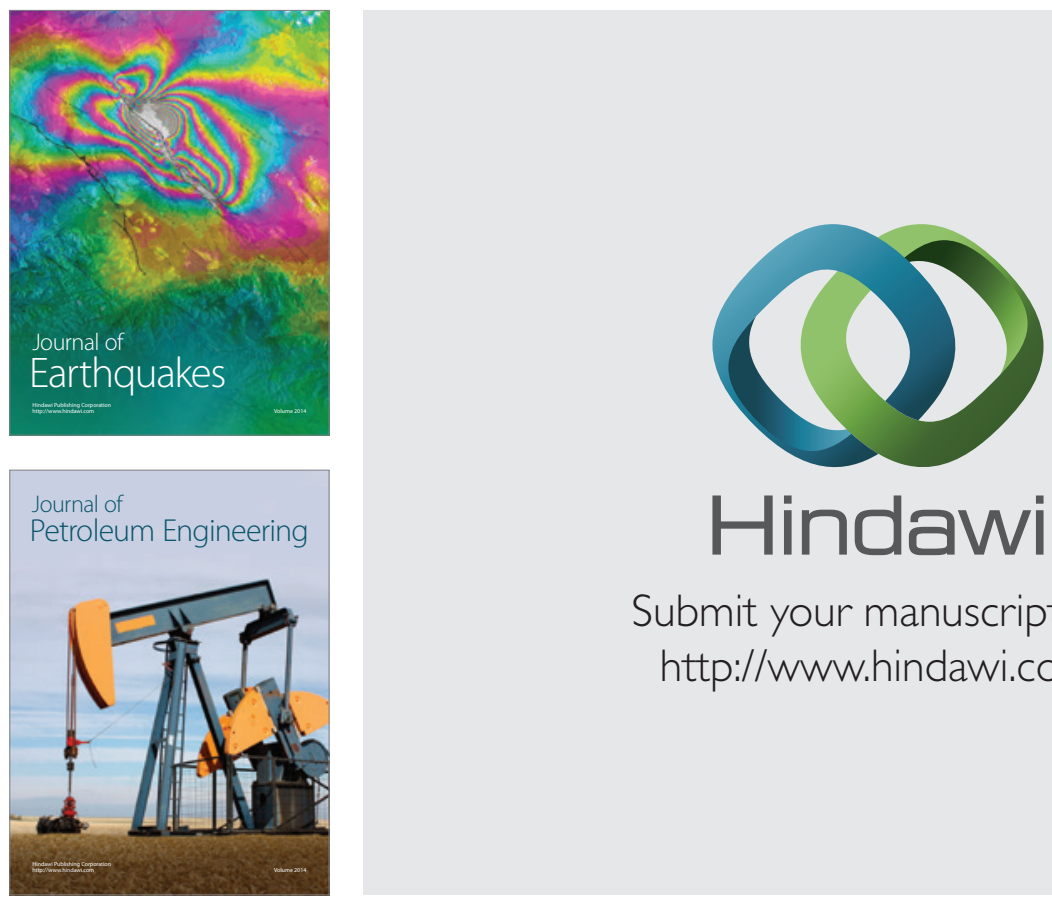

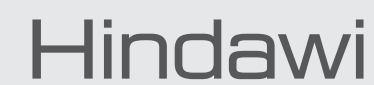

Submit your manuscripts at

http://www.hindawi.com
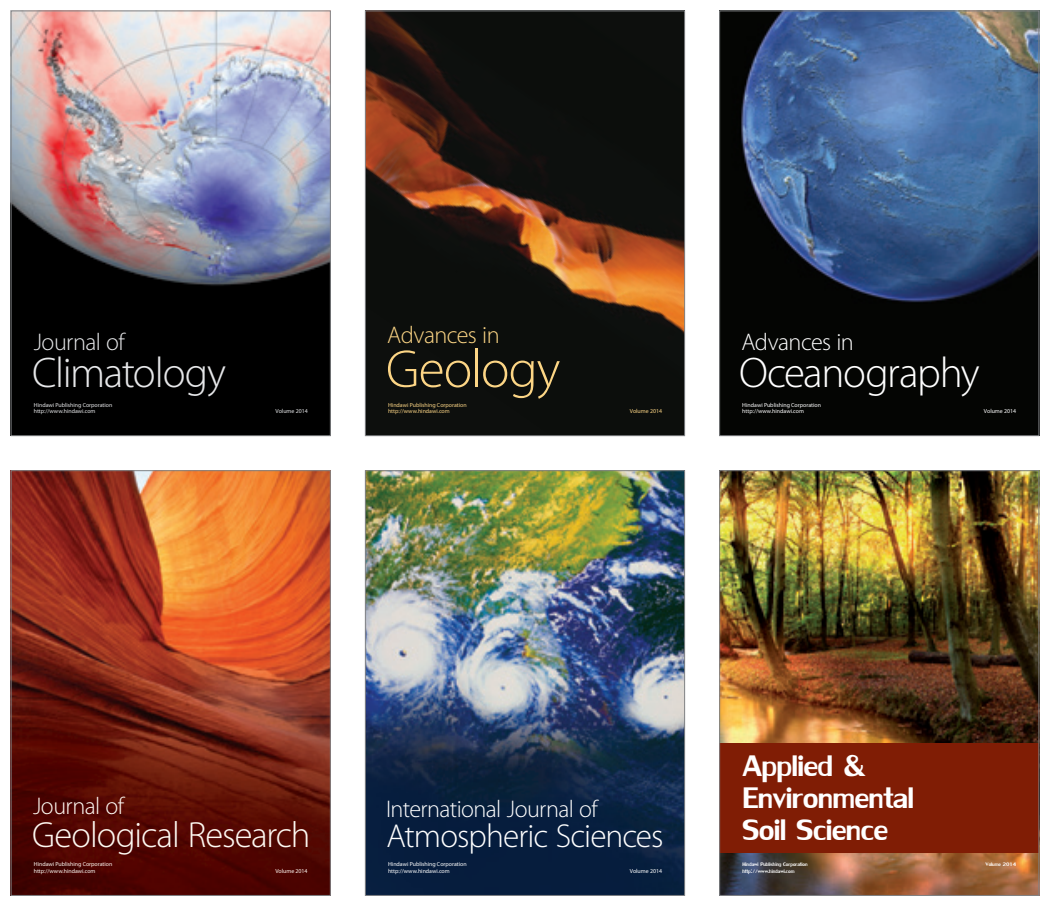
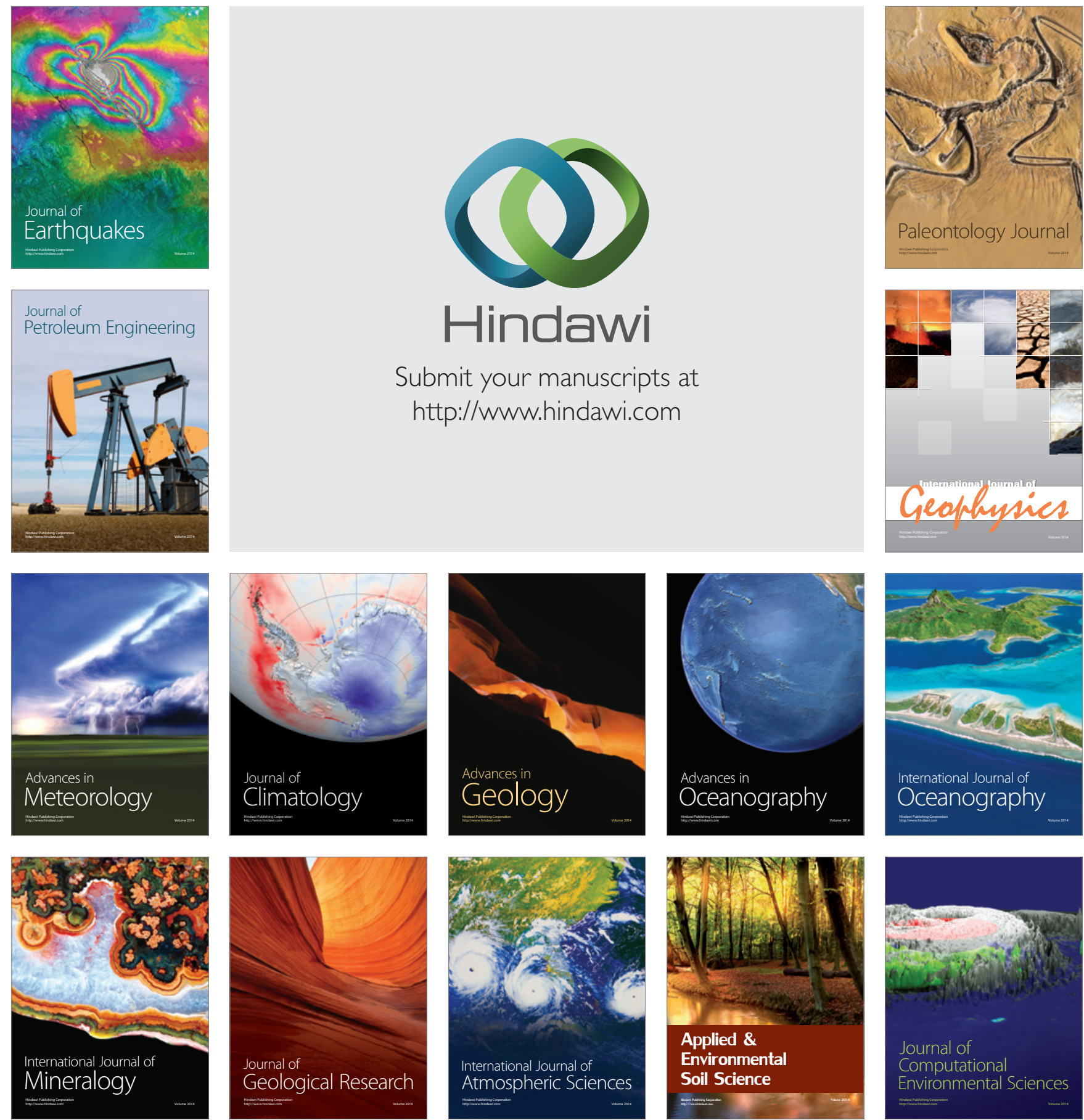